\title{
Coordination of Cooperative Advertising in a Two-Period Fashion and Textiles Supply Chain
}

\author{
Yi He, Zhiying Liu, and Khalid Usman \\ School of Management, University of Science and Technology of China, Hefei, Anhui 232206, China \\ Correspondence should be addressed to Zhiying Liu; liuzhiy@ustc.edu.cn
}

Received 21 March 2014; Revised 5 May 2014; Accepted 23 May 2014; Published 9 June 2014

Academic Editor: Xiaohang Yue

Copyright ( 2014 Yi He et al. This is an open access article distributed under the Creative Commons Attribution License, which permits unrestricted use, distribution, and reproduction in any medium, provided the original work is properly cited.

\begin{abstract}
Previous studies related to cooperative advertising mainly focus on the one-period supply chain. In the fashion and textiles (FT) supply chain, the demand of most FT products (fashion clothing, vogue handbags, fashion shoes, and so on) varies over time due to the trends of fashion. In these conditions, a decision-making framework with a multiple-period supply chain becomes more realistic. In view of this, we investigate the optimal cooperative advertising strategies in a two-period FT supply chain consisting of a manufacturer and a retailer in two different scenarios: (i) each channel member makes decisions within a cooperative program; (ii) the retailer is vertically integrated with a manufacturer. Also, we introduce a two-way subsidy contract to coordinate the supply chain.
\end{abstract}

\section{Introduction}

Today, the public has been paying more attention to product quality. This is especially true in the fashion and textiles (FT) industry, which has been one of the most rapidly developing industries in the world over the past decade. Therefore, many FT firms are turning to the tactic of increasing their product quality as a powerful competitive tool in the market. Quality is defined in many different ways in the operations management literature. Banker et al. used the term "quality" to refer to both design and conformance quality characteristics that are of interest to the customer when evaluating the product offered by the supply chain [1]. For FT products, we use the term "quality" to refer to highly fashionable ("trendy") product design. Owing to the fact that fashionable trends change rapidly, the effect of FT product quality on demand changes over time, which induces the consumers' demand variations; therefore, the FT supply chain could be seen as a two-period or multiple-period supply chain.

Besides improving the product quality, firms can also increase the market demand by boosting brand reputation and by engaging in promotion and advertising [2]. Cooperative advertising is a common cooperative approach between the manufacturer and the retailer, where the manufacturer pays part of the retailer's advertising costs to stimulate the retailer to advertise the manufacturer's product. Through a cooperative advertising program, the profit for each channel member may be improved [3].

In practice, cooperative advertising is now widely adopted by many firms, such as IBM, Apple Computer, and Intel [4-6]. As indicated by Dant and Berger [7], 25-40\% of local advertisements are cooperatively funded. Nagler [6] indicated that the total expenditures on cooperative advertising in 2000 were estimated at $\$ 15$ billion, while about $\$ 50$ billion was spent on the cooperative advertising program in 2010 [8]. Aside from being adopted in practice, cooperative advertising has also received significant attention in the academic field. Cooperative advertising models are mainly divided into two types: static models [9-22] and dynamic models [23-31]. Almost all of the existing studies on cooperative advertising consider a one-period supply chain; few studies focus on the two-period supply chain.

The significant contribution of our study is that it generalizes existing cooperative advertising work on the "oneperiod supply chain" framework to the "two-period supply chain" framework. This generalization has provided new analytical results about the manufacturer's subsidy policies and supply chain coordination. In detail, we propose a twoperiod cooperative advertising model for a manufacturer and a retailer FT supply chain where the demand varies in two 
different periods. We assume that FT product demand is affected by the product quality in the first period, while the effect of product quality on demand has disappeared in the second period.

Our research questions include the following. (i) What are the optimal advertising efforts for the retailer during the two periods? (ii) What are the optimal quality effort and subsidy policies for the manufacturer during the two periods? (iii) Is there a contract that can coordinate the two-period FT supply chain? To answer the above questions, we derive the optimal decisions in two different scenarios: (i) each channel member makes decisions within a cooperative program and (ii) the manufacturer and the retailer are vertically integrated. Finally, a two-way subsidy contract is proposed to coordinate the FT supply chain.

The remainder of this paper is organized as follows. The literature related to our topic is reviewed in Section 2. Section 3 develops the proposed models and then the optimal decisions in two different scenarios are discussed. A coordination strategy is proposed in Section 4. Section 5 offers a numerical analysis. Conclusion and suggestions for future research are in Section 6. Proofs of all propositions in the paper are given in the Appendix.

\section{Literature Review}

This paper contributes to several streams of research, each of which we review below. The first is fashion and textiles supply chain management. The FT industry is one of the most important industries in the world, and the FT supply chain is underresearched academically; yet it has received attention by a few researchers [32]. The market characteristics of textiles and clothing include short product lifecycle, high volatility, low predictability, and a high level of impulse purchasing [33]. Wang et al. explored the coordination problem in an FT supply chain with demand variations [32]. Chiu et al. explored the performance of sales rebate contracts in fashion supply chains with the use of real empirical data from five companies [34]. Huang et al. investigated coordination of risk management in FT supply chains organized as virtual enterprises [35]. Xu et al. incorporated the fashion retailer's risk aversion attitude along with pricing factor into a two-stage fashion supply chain and proposed both single contracts and joint contracts to achieve supply chain coordination [36]. Peng and Zhou explored the quantity discount coordination models in the fashion supply chain with uncertain yields and random demand [37]. Cheng et al. investigated and compared two quality control methods to optimize supply chain quality in the FT industry [38]. The above literature mainly concentrates on designing a feasible contract to coordinate the FT supply chain.

Cooperative advertising is a major issue in research on supply chain management. The literature related to cooperative advertising is usually divided into static and dynamic games. For the static models, the first static model of cooperative advertising was proposed by Berger [9]. Dant and Berger investigated the manufacturer's advertising cost sharing rate and the retailer's advertising efforts [7]. Distinguishing advertising into national advertising and local advertising, Huang and Li [3], Huang et al. [11], and Li et al. [12] extended the work of Berger [9] into a supply chain framework and studied the advertising decisions for different relationship configurations between the manufacturer and the retailer. Based on the work of Huang and Li [3], Yue et al. investigated the coordination of cooperative advertising in a manufacturer-retailer supply chain when a manufacturer offers discounts [14]. Xie and Neyret extended the work of Huang and Li [3] and studied the optimal pricing and cooperative advertising strategies in four classical types of relationships between a manufacturer and a retailer [17]. Yang et al. investigated the cooperative advertising strategies in a supply chain with fairness concerns [21]. Zhang et al. investigated the cooperative advertising strategies in a twotier distribution channel and extended the popular unilateral participation strategy to bilateral participations [22].

For the dynamic models, based on the work of Nerlove and Arrow [39], Chintagunta and Jain developed a dynamic model to study the equilibrium advertising levels for a manufacturer and a retailer supply chain [23]. Considering that the advertisements have both short and long term impacts on the retailer's sales, Jørgensen et al. studied the cooperative advertising strategies in a manufacturer and a retailer supply chain [24,25]. Based on the work of Jørgensen et al. [24], Karray and Zaccour investigated the cooperative advertising strategies in a supply chain when a retailer sells the manufacturer's product and his own product [28]. He et al. studied the cooperative advertising strategies in a dynamic stochastic supply chain [29]. Zhang et al. analyzed the effects of reference price on cooperative advertising decisions [30]. $\mathrm{He}$ et al. investigated the cooperative advertising strategies in a "two-manufacturer one-retailer" supply chain. To our best knowledge, cooperative advertising focused on a "twoperiod FT supply chain." Framework for the supply chain has not been explored in the literature. Therefore, we investigate cooperative advertising strategies in the two-period FT supply chain.

\section{Model Development}

We consider an FT supply chain system consisting of a manufacturer and a retailer, where the manufacturer produces and supplies FT products to the retailer and then the retailer sells the products to the end consumers. The manufacturer expends effort on quality improvement and the retailer advertises the products. As mentioned above, we use the term "quality" to refer to highly fashionable ("trendy") product design in this paper.

Different from previous models related to FT products, we consider that the effect of product quality on demand is changing over time, and this naturally divides the selling season into two periods. Denote the advertising efforts for the retailer during the two periods by $e_{1}$ and $e_{2}$ and the demand during the two periods by $D_{1}$ and $D_{2}$. In addition, the quality effort for the manufacturer is denoted by $x$. As our demand function is based upon the model of Ma et al. [2], the primary 
demand function in the first period satisfies the following equation:

$$
D_{1}=\alpha_{1}+\beta x+\lambda e_{1},
$$

where $\beta$ and $\lambda$ are both positive constants. $\alpha_{1} \gg 0$ is the potential intrinsic demand for the FT product in the first period, which is irrespective of product quality and advertising efforts. The term $\beta x$ represents the effect of product quality on the demand in the first period, and the term $\lambda e_{1}$ indicates the effect of advertising on the demand in the first period.

In our model, we assume that the product price is kept constant due to the following reasons. First, the main purpose of this paper is to investigate the cooperative advertising strategies on the two-period supply chain under the different subsidy policies and propose a contract to coordinate the supply chain. Second, in practice, it is very common for a firm to adopt the same price policy but offer different product quality in the market. For instance, in the fashion apparel industry, the brand Hailanhome from Jiangsu of China would keep the product price of its products fixed all the time [30]. Third, this assumption is also found in previous literature related to the cooperative advertising $[3,12,14,30,31]$.

In practice, consumers pay more attention to the FT products when the products just come onto the market. But as time goes on, consumers may not be attracted by the same characteristics of the FT products, which in our model mean that the product quality (i.e., the trendiness) has no effect on the consumer demand in the second period. Therefore, the primary demand function in the second period satisfies the following equation:

$$
D_{2}=\alpha_{2}+\theta \lambda e_{2}
$$

where $\alpha_{2} \gg 0$ is the potential intrinsic demand for the FT product in the second period. Here, $\theta$ is positive constant which indicates the relationship between the effect of advertising on the demand in the first period and that in the second period. If the condition $\theta<1$ holds, this means that the effect of advertising on demand in the first period is larger than that in the second period.

Similar to previous literature such as Gavious and Lowengart [40], the quality cost function is quadratic with respect to quality effort, specified by

$$
C(x)=x^{2},
$$

and the advertising cost function is quadratic with respect to advertising effort, specified by

$$
C\left(e_{i}\right)=\frac{1}{2} e_{i}^{2}, \quad i \in\{1,2\} .
$$

This assumption about the advertising cost function is commonly found in the literature [41].

Without accounting for the quality and advertising costs, we assume that the manufacturer's marginal profit for each unit to be sold in the period $i$ is $\rho_{m i}$ and the retailer's marginal profit in the period $i$ is $\rho_{r i}$. Then, the profit function for the manufacturer is given by

$$
\pi_{m}=\rho_{m 1} D_{1}+\rho_{m 2} D_{2}-x^{2},
$$

and the expected profit function for the retailer is given by

$$
\pi_{r}=\rho_{r 1} D_{1}+\rho_{r 2} D_{2}-\frac{1}{2} e_{1}^{2}-\frac{1}{2} e_{2}^{2} .
$$

Next, we will calculate the optimal quality effort and cooperative advertising strategies for the channel members in the following two different scenarios.

3.1. Each Channel Member Makes Decisions within a Cooperative Program. In this scenario, each channel member makes decisions within a cooperative program, where the cooperative program has the manufacturer provide a subsidy rate for the retailer's advertising costs. Here, we consider two situations in the cooperative program. The first situation is that the manufacturer provides different subsidy rates $\phi_{i}(0 \leq$ $\left.\phi_{i} \leq 1, i=1,2\right)$ during the two periods, and the second situation is that the manufacturer provides the same subsidy rate $\phi(0 \leq \phi \leq 1)$ during the two periods.

Decision sequences of the two channel members are described as follows: (i) the manufacturer provides the subsidy rates for the retailer's advertising costs; (ii) the manufacturer determines his quality effort in the first period; (iii) the retailer determines his advertising effort in the first period; (iv) the retailer determines his advertising effort in the second period. We firstly keep the subsidy rates fixed and calculate the quality effort of the manufacturer and the retailer's advertising efforts and then calculate the optimal subsidy rates under the four different subsidy policies.

Situation 1 (the manufacturer provides two different subsidy rates to the retailer during the two periods). In this situation, with the fixed subsidy rates $\phi_{i}$, the profit function of the manufacturer is changed into

$$
\pi_{m}=\rho_{m 1} D_{1}+\rho_{m 2} D_{2}-x^{2}-\frac{1}{2} \phi_{1} e_{1}^{2}-\frac{1}{2} \phi_{2} e_{2}^{2},
$$

and the profit function of the retailer is changed into

$$
\pi_{r}=\rho_{r 1} D_{1}+\rho_{r 2} D_{2}-\frac{1}{2}\left(1-\phi_{1}\right) e_{1}^{2}-\frac{1}{2}\left(1-\phi_{2}\right) e_{2}^{2} .
$$

For this optimization problem, utilizing (7) and (8), we obtain the following results.

Proposition 1. Under the first situation, when each channel member makes decisions within a cooperative program, and the subsidy rates $\phi_{i}$ are fixed, the optimal quality effort for the manufacturer is

$$
x^{c}=\frac{\beta \rho_{m 1}}{2},
$$

and the optimal advertising effort for the retailer in the first period is

$$
e_{1}^{c}=\frac{\lambda \rho_{r 1}}{1-\phi_{1}},
$$

and the optimal advertising effort for the retailer in the second period is

$$
e_{2}^{c}=\frac{\theta \lambda \rho_{r 2}}{1-\phi_{2}}
$$


According to Proposition 1, we get the following facts. (i) As the first-period marginal profit of the manufacturer increases, the manufacturer will spend more on the quality improvement. (ii) Whatever the subsidy rates that the manufacturer undertakes, the manufacturer's optimal quality effort is kept the same, while a higher subsidy rate will lead the retailer to spend more on advertising. (iii) The larger the retailer's first-period marginal profit is, the more the retailer will spend on advertising in the first period, and the retailer's first-period marginal profit has no impact on the retailer's second-period advertising effort.

Substituting (9)-(11) into (7) and (8), respectively, and with subsidy rates $\phi_{i}$ being fixed, we obtain the manufacturer's profit function as follows:

$$
\begin{aligned}
\pi_{m}^{c}= & \rho_{m 1}\left(\alpha_{1}+\beta x^{c}+\lambda e_{1}^{c}\right)+\rho_{m 2}\left(\alpha_{2}+\theta \lambda e_{2}^{c}\right) \\
& -\left(x^{c}\right)^{2}-\frac{1}{2} \phi_{1}\left(e_{1}^{c}\right)^{2}-\frac{1}{2} \phi_{2}\left(e_{2}^{c}\right)^{2},
\end{aligned}
$$

and the retailer's profit function is

$$
\begin{aligned}
\pi_{r}^{c}= & \rho_{r 1}\left(\alpha_{1}+\beta x^{c}+\lambda e_{1}^{c}\right)+\rho_{r 2}\left(\alpha_{2}+\theta \lambda e_{2}^{c}\right) \\
& -\frac{1}{2}\left(1-\phi_{1}\right)\left(e_{1}^{c}\right)^{2}-\frac{1}{2}\left(1-\phi_{2}\right)\left(e_{2}^{c}\right)^{2} .
\end{aligned}
$$

Here, we consider two subsidy policies (i.e., the first policy and second policy): (i) the manufacturer determines the optimal subsidy rates; (ii) the retailer and the manufacturer jointly determine the optimal subsidy rates. Under the first subsidy policy (i.e., the manufacturer determines his optimal subsidy rate), differentiating $\pi_{m}^{c}$ with respect to the subsidy rates $\phi_{i}$, respectively, we obtain the optimal subsidy rates, which are given by Proposition 2 .

Proposition 2. When each channel member makes decisions within a cooperative program, the optimal subsidy rates that the manufacturer provides to the retailer under the first subsidy policy are

$$
\begin{aligned}
\phi_{i}^{1}= \begin{cases}\frac{2 \rho_{m i}-\rho_{r i}}{2 \rho_{m i}+\rho_{r i}} & \text { if } \rho_{m i}>\frac{1}{2} \rho_{r i} \\
0 & \text { else, }\end{cases} \\
\quad i \in\{1,2\} .
\end{aligned}
$$

From (14), the restraining condition $\rho_{m i}>0.5 \rho_{r i}$ implies that the manufacturer is willing to provide the subsidy rate to the retailer only when he can obtain a large enough marginal profit. Differentiating the manufacturer's optimal subsidy rates $\phi_{i}^{1}$ with respect to the marginal profits of all channel members when $\rho_{m i}>0.5 \rho_{r i}$, we have $\partial \phi_{i}^{1} / \partial \rho_{m i}>0$ and $\partial \phi_{i}^{1} / \partial \rho_{r i}<0$. For the first period, these two expressions imply that (i) as the manufacturer's first-period marginal profit increases, the manufacturer will provide a high subsidy rate to the retailer in the first period; (ii) an increase in the retailer's first-period marginal profit will decrease the manufacturer's subsidy rate. When the retailer obtains a low marginal profit, from (14), we find that the manufacturer should provide a large subsidy rate to stimulate the retailer to do more advertising. This conclusion was also reached by previous studies [3, 30, 31]. (iii) The optimal subsidy rate is only affected by the marginal profits of the current period and does not depend on the other period's marginal profit. Considering the second period, we can get similar results. Under the second subsidy policy, the manufacturer and the retailer jointly determine the optimal subsidy rates. Differentiating profit of the total supply chain (i.e., $\pi_{m}^{c}+\pi_{r}^{c}$ ) with respect to the subsidy rates $\phi_{i}$, respectively, we obtain the optimal subsidy rates, which are given by Proposition 3.

Proposition 3. When each channel member makes decisions within a cooperative program, the optimal subsidy rates that the manufacturer provides to the retailer under the second subsidy policy are

$$
\phi_{i}^{2}=\frac{\rho_{m i}}{\rho_{m i}+\rho_{r i}}, \quad i \in\{1,2\}
$$

According to (15), the optimal subsidy rate is equal to manufacturer's marginal profit ratio in the same period. We also obtain similar results to those of Proposition 2. By comparison with (14), we obtain $\phi_{1}^{2}>\phi_{1}^{1}$ and $\phi_{2}^{2}>\phi_{2}^{1}$, which imply that the subsidy rates under the second subsidy policy are higher than those under the first subsidy policy. These results also lead to the conclusion that the retailer will spend more on advertising during two periods if the manufacturer adopts the second subsidy policy.

Together with the results of Propositions 1-3, under the first subsidy policy, we obtain both channel members' efforts (i.e., $x^{1 c}, e_{1}^{1 c}$, and $e_{2}^{1 c}$ ) and the profits (i.e., $\pi_{m}^{1 c}$ and $\left.\pi_{r}^{1 c}\right)$. Similarly, under the second subsidy policy, we get both channel members' efforts (i.e., $x^{2 c}, e_{1}^{2 c}$, and $e_{2}^{2 c}$ ) and profits (i.e., $\pi_{m}^{2 c}$ and $\pi_{r}^{2 c}$ ).

Situation 2 (the manufacturer provides the same subsidy rate to the retailer during the two periods). In this situation, with a fixed subsidy rate, the profit function of the manufacturer is changed into

$$
\pi_{m}=\rho_{m 1} D_{1}+\rho_{m 2} D_{2}-x^{2}-\frac{1}{2} \phi e_{1}^{2}-\frac{1}{2} \phi e_{2}^{2},
$$

and the profit function of the retailer is changed into

$$
\pi_{r}=\rho_{r 1} D_{1}+\rho_{r 2} D_{2}-\frac{1}{2}(1-\phi) e_{1}^{2}-\frac{1}{2}(1-\phi) e_{2}^{2} .
$$

For this optimization problem, utilizing (16) and (17), we obtain the following results.

Proposition 4. Under the second situation, when each channel member makes decisions within a cooperative program, and the subsidy rate $\phi$ is fixed, the optimal quality effort for the manufacturer is

$$
x^{c}=\frac{\beta \rho_{m 1}}{2},
$$

and the optimal advertising effort for the retailer in the first period is

$$
e_{1}^{c}=\frac{\lambda \rho_{r 1}}{1-\phi},
$$


and the optimal advertising effort for the retailer in the second period is

$$
e_{2}^{c}=\frac{\theta \lambda \rho_{r 2}}{1-\phi} .
$$

Together with the results of Proposition 1, we find that in the second situation, the optimal advertising efforts have a similar structure to that in the first situation. Additionally, the manufacturer does not change his optimal quality effort in either of the two situations, which indicates that the optimal quality effort does not depend on the subsidy policy which the manufacturer adopts.

Substituting (18)-(20) into (16) and (17), respectively, and with subsidy rate $\phi$ being fixed, we obtain the manufacturer's profit as follows:

$$
\begin{aligned}
\pi_{m}^{c}= & \rho_{m 1}\left(\alpha_{1}+\beta x^{c}+\lambda e_{1}^{c}\right)+\rho_{m 2}\left(\alpha_{2}+\theta \lambda e_{2}^{c}\right) \\
& -\left(x^{c}\right)^{2}-\frac{1}{2} \phi\left(e_{1}^{c}\right)^{2}-\frac{1}{2} \phi\left(e_{2}^{c}\right)^{2},
\end{aligned}
$$

and the retailer's profit function is

$$
\begin{aligned}
\pi_{r}^{c}= & \rho_{r 1}\left(\alpha_{1}+\beta x^{c}+\lambda e_{1}^{c}\right)+\rho_{r 2}\left(\alpha_{2}+\theta \lambda e_{2}^{c}\right) \\
& -\frac{1}{2}(1-\phi)\left(e_{1}^{c}\right)^{2}-\frac{1}{2}(1-\phi)\left(e_{2}^{c}\right)^{2} .
\end{aligned}
$$

Here, we also consider two subsidy policies (i.e., the third policy and fourth policy): (i) the manufacturer determines the optimal subsidy rates and (ii) the retailer and the manufacturer jointly determine the optimal subsidy rates. First, we consider the third subsidy policy, in which the manufacturer determines his optimal subsidy rate. By differentiating $\pi_{m}^{c}$ with respect to the subsidy rate $\phi$, we obtain the optimal subsidy rate, which is given by Proposition 5 .

Proposition 5. When each channel member makes decisions within a cooperative program, the optimal subsidy rate that the manufacturer provides to the retailer under the third subsidy policy is

$$
\phi^{3}=\left\{\begin{array}{l}
\frac{2 \rho_{m 1} \rho_{r 1}+2 \rho_{m 2} \rho_{r 2} \theta^{2}-\rho_{r 1}^{2}-\rho_{r 2}^{2} \theta^{2}}{2 \rho_{m 1} \rho_{r 1}+2 \rho_{m 2} \rho_{r 2} \theta^{2}+\rho_{r 1}^{2}+\rho_{r 2}^{2} \theta^{2}} \\
\quad \text { if } \frac{\rho_{m 1} \rho_{r 1}+\rho_{m 2} \rho_{r 2} \theta^{2}}{\rho_{r 1}^{2}+\rho_{r 2}^{2} \theta^{2}}>\frac{1}{2} \\
0 \quad \text { else. }
\end{array}\right.
$$

For (23), differentiating $\phi^{3}$ with respect to $\rho_{m i}$ and $\rho_{r i}$ and knowing that $\rho_{m 1} \rho_{r 1}+\rho_{m 2} \rho_{r 2} \theta^{2}>0.5\left(\rho_{r 1}^{2}+\rho_{r 2}^{2} \theta^{2}\right)$, we have $\partial \phi^{3} / \partial \rho_{m i}>0$, which implies that as the manufacturer's marginal profit increases, he will provide a higher subsidy rate to the retailer. If the condition $2 \rho_{m 2} / \rho_{r 2} \geq \rho_{m 1} / \rho_{r 1}$ holds, we get $\partial \phi^{3} / \partial \rho_{r 1}<0$. Similarly, when the condition $2 \rho_{m 1} / \rho_{r 1} \geq$ $\rho_{m 2} / \rho_{r 2}$ is satisfied, we obtain $\partial \phi^{3} / \partial \rho_{r 2}<0$. Different from the first and second subsidy policies, an increase in retailer's marginal profit does not always decrease the optimal subsidy rate under the third subsidy policy. This result is different from the previous studies (i.e., Huang and Li [3], Zhang et al. [30], and He et al. [31]); the optimal subsidy rate is not always decreased by the retailer's marginal profit in the two-period supply chain when the manufacturer adopts the same subsidy policy.

By comparison with (14), when the condition $\rho_{m 1} / \rho_{r 1}>$ $\rho_{m 2} / \rho_{r 2}$ holds, we have $\phi_{2}^{1}<\phi^{3}<\phi_{1}^{1}$. To be specific, if the marginal profit ratio of the manufacturer and retailer in the first period is higher than that in the second period, the value of the optimal subsidy rate under the third subsidy policy is between the values of both subsidy rates under the first subsidy policy.

Under the fourth subsidy policy, the manufacturer and the retailer jointly determine the optimal subsidy rate. Differentiating $\pi_{m}^{c}+\pi_{r}^{c}$ with respect to the subsidy rate $\phi$, we get the optimal subsidy rate, which is given by Proposition 6 .

Proposition 6. When each channel member makes decisions within a cooperative program, the optimal subsidy rate that the manufacturer provides to the retailer under the fourth subsidy policy is

$$
\phi^{4}=\frac{\rho_{m 1} \rho_{r 1}+\rho_{m 2} \rho_{r 2} \theta^{2}}{\rho_{m 1} \rho_{r 1}+\rho_{r 1}^{2}+\rho_{m 2} \rho_{r 2} \theta^{2}+\rho_{r 2}^{2} \theta^{2}} .
$$

According to (24), differentiating $\phi^{3}$ from $\rho_{m i}$ and $\rho_{r i}$, we obtain results similar to those of Proposition 5. By comparison with (23), we get $\phi^{4}>\phi^{3}$, which implies that the subsidy rate under the fourth subsidy policy is higher than that under the third subsidy policy. This result leads to the conclusion that the retailer will spend more on advertising during the two periods if the manufacturer adopts the fourth subsidy policy. Together with the results of Proposition 3, we get the following fact: when the retailer and the manufacturer jointly determine the subsidy rates, the optimal subsidy rates are higher than when they are determined by the manufacturer alone.

Then, together with the results of Propositions 4-6, under the third subsidy policy, we obtain both firms' efforts (i.e., $x^{3 c}$, $e_{1}^{3 c}$, and $e_{2}^{3 c}$ ) and the profits (i.e., $\pi_{m}^{3 c}$ and $\pi_{r}^{3 c}$ ). Similarly, under the fourth subsidy policy, we get both firms' efforts (i.e., $x^{4 c}$, $e_{1}^{4 c}$, and $e_{2}^{4 c}$ ) and profits (i.e., $\pi_{m}^{4 c}$ and $\pi_{r}^{4 c}$ ).

3.2. The Manufacturer Vertically Integrates with Retailer. In this scenario, the manufacturer and the retailer are vertically integrated; they determine the quality effort and advertising efforts by maximizing the joint channel profit. Therefore, the profit function of the integrated system is $\pi_{I}=\pi_{m}+\pi_{r}$.

For this optimization problem, we obtain the following results.

Proposition 7. When the manufacturer integrates with the retailer, the optimal quality improvement effort for the manufacturer is

$$
x^{I}=\frac{1}{2} \beta\left(\rho_{m 1}+\rho_{r 1}\right) \text {, }
$$


and the optimal advertising effort for the retailer in the first period is

$$
e_{1}^{I}=\lambda\left(\rho_{m 1}+\rho_{r 1}\right)
$$

and the optimal advertising effort for the retailer in the second period is

$$
e_{2}^{I}=\theta \lambda\left(\rho_{m 2}+\rho_{r 2}\right) .
$$

In Proposition 7, we get the following results: (i) the optimal quality effort for the manufacturer is affected by the first-period marginal profit of the total supply chain, and the quality effort under the integrated scenario is larger than that under the cooperative program; (ii) for the retailer, the first-period advertising effort is affected by the the firstperiod marginal profit of the total supply chain and is not just dependent on the retailer's first-period marginal profit.

\section{A Two-Way Subsidy Contract}

In this section, we introduce a two-way subsidy contract to coordinate the supply chain. The two-way subsidy contract works as follows: the manufacturer offers subsidy rates $\phi_{i}\left(0 \leq \phi_{i} \leq 1, i=1,2\right)$ for the retailer's advertising cost during the two periods; meanwhile, the retailer also shares a part of the manufacturer's quality improvement cost with a subsidy rate of $\psi$. Decision sequences of the two channel members are described as follows: first, the two firms determine each firm's subsidy rates. Second, the manufacturer determines his quality effort. Third, the retailer determines his advertising efforts during the two periods.

Under the two-way subsidy contract, the profit functions for the manufacturer and the retailer in (5) and (6) are then changed into

$$
\pi_{m}=\rho_{m 1} D_{1}+\rho_{m 2} D_{2}-(1-\psi) x^{2}-\frac{1}{2} \phi_{1} e_{1}^{2}-\frac{1}{2} \phi_{2} e_{2}^{2},
$$

and the profit function of the retailer is changed into

$$
\pi_{r}=\rho_{r 1} D_{1}+\rho_{r 2} D_{2}-\psi x^{2}-\frac{1}{2}\left(1-\phi_{1}\right) e_{1}^{2}-\frac{1}{2}\left(1-\phi_{2}\right) e_{2}^{2} .
$$

For this optimization problem, utilizing (28) and (29), we obtain the following results.

Proposition 8. When the two channel members work under a two-way subsidy contract as proposed above and the subsidy rates $\psi, \phi_{1}$, and $\phi_{2}$ are fixed, the optimal quality improvement effort for the manufacturer is

$$
x^{*}=\frac{\beta \rho_{m 1}}{2(1-\psi)},
$$

and the optimal advertising effort for the retailer in the first period is

$$
e_{1}^{*}=\frac{\lambda \rho_{r 1}}{1-\phi_{1}}
$$

and the optimal advertising effort for the retailer in the second period is

$$
e_{2}^{*}=\frac{\theta \lambda \rho_{r 2}}{1-\phi_{2}}
$$

The above expressions have a structure similar to that under the cooperative program. As the subsidy rates increase, the manufacturer will spend more on the quality improvement and the retailer also does more advertising. Once there exist specific values of $\psi, \phi_{1}$, and $\phi_{2}$, that can lead to optimal efforts given by (30)-(32) equaling those given by (25)-(27), respectively, the supply chain can be coordinated. Letting $x^{*}=x^{I}, e_{1}^{*}=e_{1}^{I}$, and $e_{2}^{*}=e_{2}^{I}$ and solving the three equations, we obtain the following results.

Proposition 9. When the subsidy rates $\psi, \phi_{1}$, and $\phi_{2}$ of the two channel members take the following values

$$
\begin{aligned}
\psi^{*} & =\frac{\rho_{r 1}}{\rho_{m 1}+\rho_{r 1}}, \\
\phi_{1}^{*} & =\frac{\rho_{m 1}}{\rho_{m 1}+\rho_{r 1}}, \\
\phi_{2}^{*} & =\frac{\rho_{m 2}}{\rho_{m 2}+\rho_{r 2}},
\end{aligned}
$$

the optimal quality improvement effort for the manufacturer and the optimal advertising efforts for the retailer under the coordinated system are the same as those under the integrated system, and thus the supply chain system considered is coordinated.

Equation (33) illustrates the following facts: (i) each channel member would provide a high subsidy rate if he could obtain a large margin in a period; (ii) the subsidy rate which the retailer should provide is equal to the ratio between his first-period marginal profit and that of the total supply chain; (iii) the first-period subsidy rate which the manufacturer should offer is equal to the ratio between his first-period marginal profit and that of the total supply chain (i.e., when the retailer gets a small margin, he could provide a low subsidy rate to the manufacturer). Our study extends the work of Zhang et al. [30] and shows that the two-way subsidy contract can coordinate both the one-period and two-period advertising models.

Together with Propositions 8 and 9, we obtain two firms' profits (i.e., $\pi_{m}^{*}$ and $\pi_{r}^{*}$ ). Here, the profit of the total supply chain $\left(\pi_{m}^{*}+\pi_{r}^{*}\right)$ has been improved under the two-way subsidy contract compared with that under the cooperative program.

\section{Numerical Analysis}

In this section, we use numerical analysis to further illustrate the impacts of the subsidy policies and the contract on the profits for all channel members and supplement insights from these theoretical results. In our numerical analysis, we consider the following values: $\alpha_{1}=500, \alpha_{2}=300, \beta=5$, 


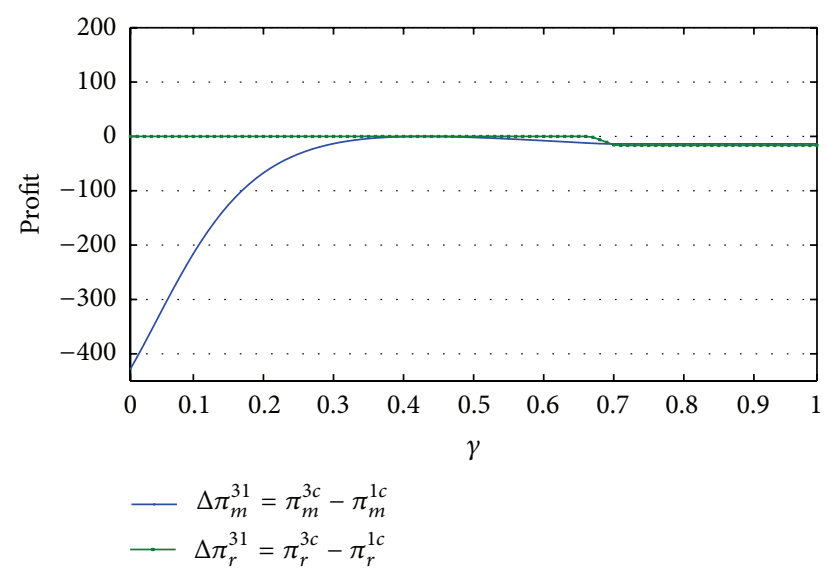

FIGURE 1: Relationships between profit and marginal profit ratio under the different subsidy polices.

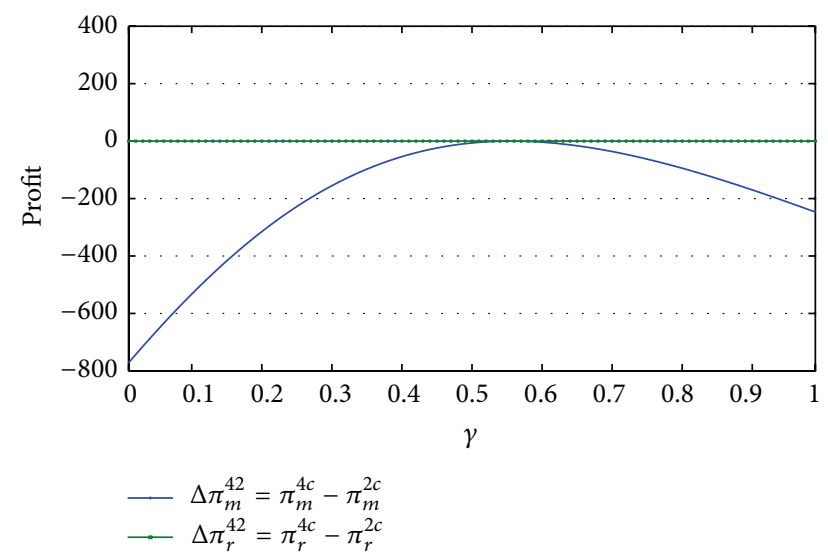

FIGURE 2: Relationships between profit and marginal profit ratio under the different subsidy polices.

$\lambda=4, \theta=0.7, \rho_{m 2}=4, \rho_{r 2}=3$, and $\rho_{m 1}+\rho_{r 1}=10$, and define the value of the $x$-axis $\gamma$ as $\gamma=\rho_{r 1} /\left(\rho_{m 1}+\rho_{r 1}\right)$, which represents the retailer's marginal profit ratio in the total supply chain in the first period. A large $\gamma$ means that the retailer achieves more of the total supply chain marginal profit in the first period.

To obtain qualitative insights regarding how the current value of each channel member's profits varies as the retailer's marginal profit varies under the two different situations (different subsidy rates and same subsidy rate), we keep the other parameters fixed and draw the relationships in Figures 1 and 2 .

Using Figures 1 and 2, we obtain the following facts: (i) if the manufacturer offers the same subsidy rate to the retailer during the two periods, the profits for the manufacturer and the supply chain system would suffer. Thus, the manufacturer is not willing to provide the same subsidy rate to the retailer during the two periods. (ii) Whether the manufacturer offers the same subsidy rate to the retailer or not, the profit for the retailer is nearly invariable.

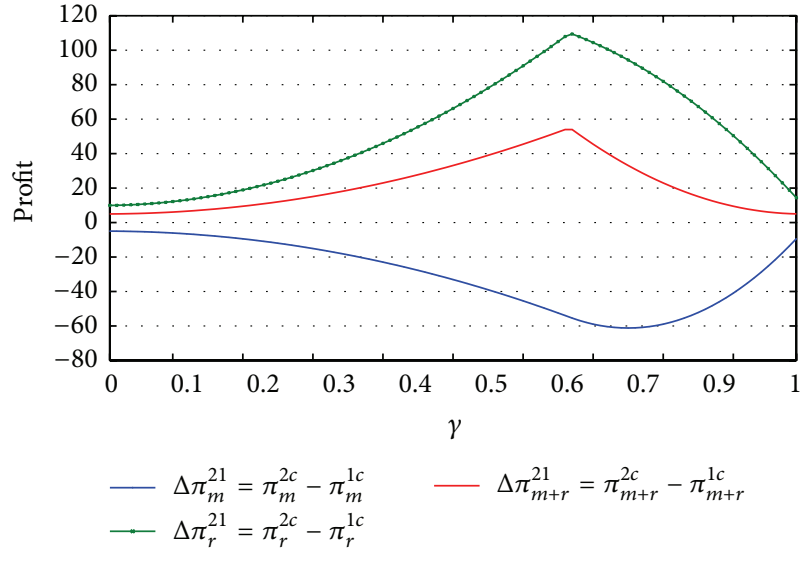

FIGURE 3: Relationships between profit and marginal profit ratio under the different subsidy polices.

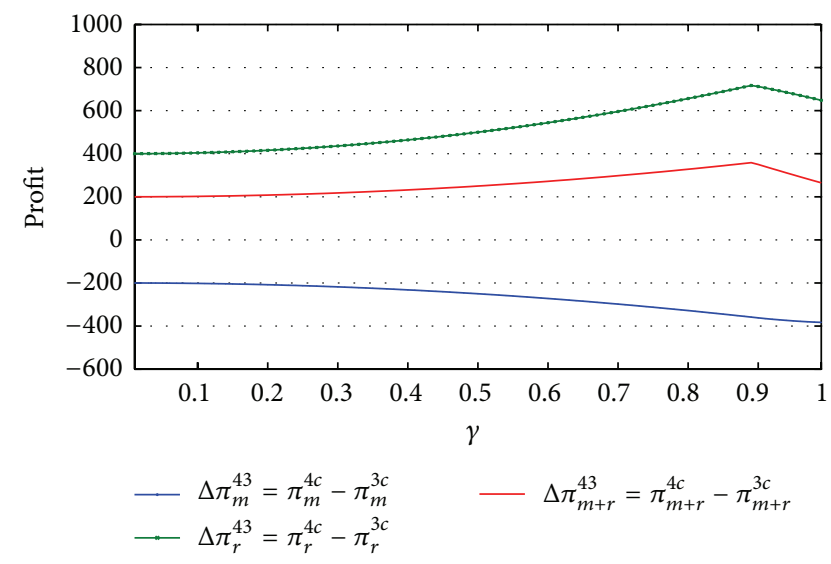

FIGURE 4: Relationships between profit and marginal profit ratio under the different subsidy polices.

Next, we will illustrate the impacts of the subsidy policies (e.g., the manufacturer determines the optimal subsidy rates, and the retailer and the manufacturer jointly determine the optimal subsidy rates) on the profits for all channel members. We keep the other parameters fixed and draw the relationships in Figures 3 and 4.

From Figures 3 and 4, we find the following results: (i) if the retailer and the manufacturer jointly determine the optimal subsidy rates, the profits for the retailer and the supply chain system would be improved, while the manufacturer's profit will suffer. If the retailer can provide a transfer payment to the manufacturer to compensate the loss, both firms can get an extra benefit from this subsidy policy.

From Figures 1 and 2, we find that the channel member should choose the subsidy policy in which the manufacturer offers different subsidy rates to the retailer during the two periods. Next, we will compare the channel members' profits under the two scenarios (e.g., Situation 1 and the contract), keep the other parameters fixed, and draw the relationships in Figures 5 and 6. 


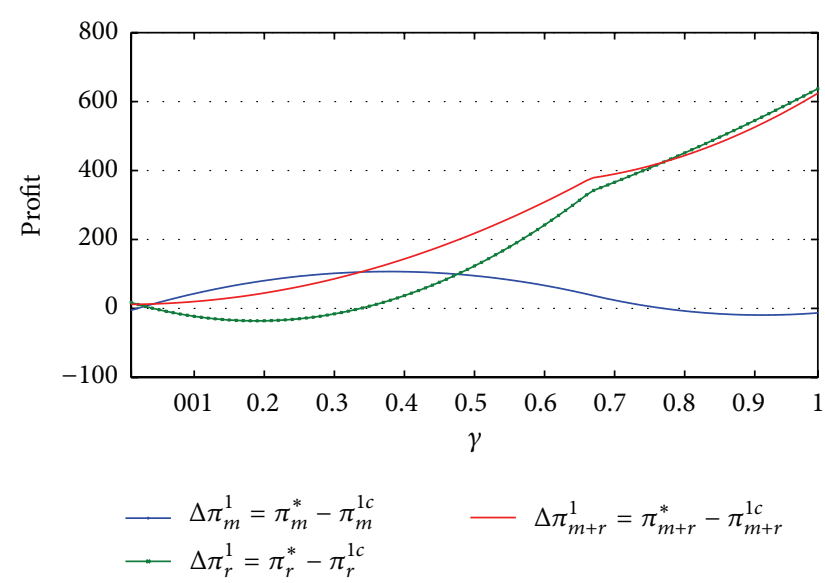

FIGURE 5: Relationships between profit and marginal profit ratio under the different scenarios.

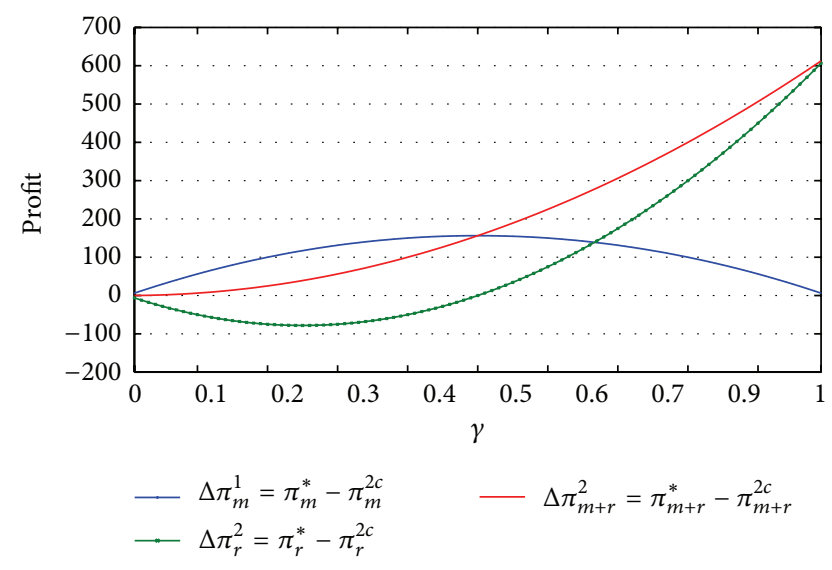

FIGURE 6: Relationships between profit and marginal profit ratio under the different scenarios.

From Figures 5 and 6, we can obtain the following facts: (i) as the retailer's marginal profit ratio varies, the total supply chain always has an improvement in profit. (ii) While the increase of the retailer's first-period marginal profit ratio will lead to the profit gap for the retailer decreasing at first, the profit gap then increases continuously after it reaches its minimum. It is very interesting to find that when the retailer's first-period marginal profit ratio is high, there is a significant profit improvement for the total supply chain and the retailer. (iii) When the retailer's first-period marginal profit ratio is low, the retailer's benefit suffers under the twoway subsidy contract, but when the retailer's marginal profit ratio is high, the manufacturer's benefit may suffer under the two-way subsidy contract. Therefore, under the two-way subsidy contract, one firm's benefit may suffer as the ratio $\gamma$ varies; then, this firm may not be willing to sign this contract. However, if the other firm provides a transfer payment to compensate this firm's loss, both firms can get an extra benefit from the two-way subsidy contract.

\section{Conclusion}

The FT supply chain system considered here consists of a manufacturer and a retailer, and we consider a two-period cooperative advertising model. Then, we calculate and compare the optimal cooperative strategies for the manufacturer and retailer in two different scenarios: (i) each channel member makes decisions within a cooperative program and (ii) the manufacturer and the retailer are vertically integrated. Then, a two-way subsidy contract is offered to coordinate the two-period FT supply chain.

The main contributions of our study include the following: (i) while most previous literature related to cooperative advertising focuses on the one-period supply chain, we investigate the optimal cooperative advertising strategies in the two-period supply chain. (ii) We analyze effects of different subsidy policies on all channel member's decisions and profits. (iii) The manufacturer tends to provide different subsidy rates to the retailer during the two periods. (iv) We prove that the two-way subsidy contract can coordinate the two-period FT supply chain.

Our study has some limitations that present directions for future research. First, it should be noted that our models assume that the price is held constant. It may be more interesting if we introduce the factor of pricing into the model. Second, we consider a supply chain system including one manufacturer and one retailer. As a direction for further research, the supply chain system could be extended to a one-manufacturer multiple-retailers framework or other frameworks.

\section{Appendix}

Proof of Propositions 1-3. Using backward induction and solving the first-order condition of $\pi_{r}$ with respect to $e_{2}$ yield

$$
e_{2}^{*}=\frac{\theta \lambda \rho_{r 2}}{1-\phi_{2}}
$$

Substituting (A.1) into (8) and solving the first-order condition of $\pi_{r}$ with respect to $e_{1}$ yield

$$
e_{1}^{*}=\frac{\lambda \rho_{r 1}}{1-\phi_{1}} .
$$

Substituting (A.1) and (A.2) into (7) and solving the firstorder condition of $\pi_{m}$ with respect to $x$ yield

$$
x^{*}=\frac{1}{2} \beta \rho_{m 1} \text {. }
$$

(i) When the manufacturer determines the optimal subsidy rates, substituting (A.1)-(A.3) into (7) and solving the first-order condition of $\pi_{m}$ with respect to $\phi_{1}$ and $\phi_{2}$ yield

$$
\begin{aligned}
\phi_{i}^{1}= \begin{cases}\frac{2 \rho_{m i}-\rho_{r i}}{2 \rho_{m i}+\rho_{r i}} & \text { if } \rho_{m i}>\frac{1}{2} \rho_{r i}, \\
0 & \text { else, }\end{cases} \\
\quad i \in\{1,2\} .
\end{aligned}
$$


(ii) If the retailer and the manufacturer jointly determine the optimal subsidy rates, substituting (A.1)-(A.3) into the integrated system (the manufacturer and the retailer) and solving the first-order condition of $\pi_{m}+$ $\pi_{r}$ with respect to $\phi_{1}$ and $\phi_{2}$ yield

$$
\phi_{i}^{2}=\frac{\rho_{m i}}{\rho_{m i}+\rho_{r i}}, \quad i \in\{1,2\} .
$$

Proof of Propositions 4-6. Using backward induction and solving the first-order condition of $\pi_{r}$ with respect to $e_{2}$ yield

$$
e_{2}^{*}=\frac{\theta \lambda \rho_{r 2}}{1-\phi} \text {. }
$$

Substituting (A.6) into (17) and solving the first-order condition of $\pi_{r}$ with respect to $e_{1}$ yield

$$
e_{1}^{*}=\frac{\lambda \rho_{r 1}}{1-\phi} \text {. }
$$

Substituting (A.6) and (A.7) into (16) and solving the firstorder condition of $\pi_{m}$ with respect to $x$ yield

$$
x^{*}=\frac{1}{2} \beta \rho_{m 1} \text {. }
$$

(i) When the manufacturer determines the optimal subsidy rates, substituting (A.6)-(A.8) into (16) and solving the first-order condition of $\pi_{m}$ with respect to $\phi$ yield

$$
\phi^{3}=\left\{\begin{array}{l}
\frac{2 \rho_{m 1} \rho_{r 1}+2 \rho_{m 2} \rho_{r 2} \theta^{2}-\rho_{r 1}^{2}-\rho_{r 2}^{2} \theta^{2}}{2 \rho_{m 1} \rho_{r 1}+2 \rho_{m 2} \rho_{r 2} \theta^{2}+\rho_{r 1}^{2}+\rho_{r 2}^{2} \theta^{2}} \\
\quad \text { if } \frac{\rho_{m 1} \rho_{r 1}+\rho_{m 2} \rho_{r 2} \theta^{2}}{\rho_{r 1}^{2}+\rho_{r 2}^{2} \theta^{2}}>\frac{1}{2} \\
0 \quad \text { else. }
\end{array}\right.
$$

(ii) If the retailer and the manufacturer jointly determine the optimal subsidy rates, substituting (A.6)-(A.8) into the integrated system (the manufacturer and the retailer) and solving the first-order condition of $\pi_{m}+$ $\pi_{r}$ with respect to $\phi$ yield

$$
\phi^{4}=\frac{\rho_{m 1} \rho_{r 1}+\rho_{m 2} \rho_{r 2} \theta^{2}}{\rho_{m 1} \rho_{r 1}+\rho_{r 1}{ }^{2}+\rho_{m 2} \rho_{r 2} \theta^{2}+\rho_{r 2}{ }^{2} \theta^{2}} .
$$

Proof of Proposition 7. Using backward induction and solving the first-order condition of the integrated system with respect to $e_{2}$ yield

$$
e_{2}^{I}=\theta \lambda\left(\rho_{m 2}+\rho_{r 2}\right) \text {. }
$$

Substituting (A.11) into the integrated system and solving the first-order condition of $\pi_{m}+\pi_{r}$ with respect to $e_{1}$ yield

$$
e_{1}^{I}=\lambda\left(\rho_{m 1}+\rho_{r 1}\right) \text {. }
$$

Substituting (A.11) and (A.12) into the integrated system and solving the first-order condition of $\pi_{m}+\pi_{r}$ with respect to $x$ yield

$$
x^{I}=\frac{1}{2} \beta\left(\rho_{m 1}+\rho_{r 1}\right) .
$$

Proof of Proposition 8. Using backward induction and solving the first-order condition of $\pi_{r}$ with respect to $e_{2}$ yield

$$
e_{2}^{*}=\frac{\theta \lambda \rho_{r 2}}{1-\phi_{2}} .
$$

Substituting (A.14) into (29) and solving the first-order condition of $\pi_{r}$ with respect to $e_{1}$ yield

$$
e_{1}^{*}=\frac{\lambda \rho_{r 1}}{1-\phi_{1}} \text {. }
$$

Substituting (A.14) and (A.15) into (28) and solving the first-order condition of $\pi_{m}$ with respect to $x$ yield

$$
x^{*}=\frac{\beta \rho_{m 1}}{2(1-\psi)} \text {. }
$$

\section{Conflict of Interests}

The authors declare that there is no conflict of interests regarding the publication of this paper.

\section{Acknowledgment}

This work was supported by the National Natural Science Foundation of China (Grant no. 71172213).

\section{References}

[1] R. D. Banker, I. Khosla, and K. K. Sinha, "Quality and competition," Management Science, vol. 44, no. 9, pp. 1179-1192, 1998.

[2] P. Ma, H. Wang, and J. Shang, "Supply chain channel strategies with quality and marketing effort-dependent demand," International Journal of Production Economics, vol. 144, no. 2, pp. 572581, 2013.

[3] Z. Huang and S. X. Li, "Co-op advertising models in manufacturer-retailer supply chains: a game theory approach," European Journal of Operational Research, vol. 135, no. 3, pp. 527-544, 2001.

[4] L. Brennan, "How retailers are putting it all together?" Sales and Marketing Management, vol. 5, pp. 62-65, 1988.

[5] S. Clark, "Dual destiny," Adweek, vol. 41, pp. 60-66, 2000.

[6] M. G. Nagler, "An exploratory analysis of the determinants of cooperative advertising participation rates," Marketing Letters, vol. 17, no. 2, pp. 91-102, 2006. 
[7] R. P. Dant and P. D. Berger, "Modelling cooperative advertising decisions in franchising," Journal of the Operational Research Society, vol. 47, no. 9, pp. 1120-1136, 1996.

[8] R. Yan, "Cooperative advertising, pricing strategy and firm performance in the e-marketing age," Journal of the Academy of Marketing Science, vol. 38, no. 4, pp. 510-519, 2010.

[9] P. D. Berger, "Vertical cooperative advertising ventures," Journal Marketing Research, vol. 9, no. 3, pp. 309-312, 1972.

[10] M. Bergen and G. John, "Understanding cooperative advertising participation rates in conventional channels," Journal of Marketing Research, vol. 34, no. 3, pp. 357-369, 1997.

[11] Z. Huang, S. X. Li, and V. Mahajan, "An analysis of manufacturer-retailer supply chain coordination in cooperative advertising," Decision Sciences, vol. 33, no. 3, pp. 469-494, 2002.

[12] S. X. Li, Z. Huang, J. Zhu, and P. Y. K. Chau, "Cooperative advertising, game theory and manufacturer-retailer supply chains," Omega, vol. 30, no. 5, pp. 347-357, 2002.

[13] P. D. Berger, J. Lee, and B. D. Weinberg, "Optimal cooperative advertising integration strategy for organizations adding a direct online channel," Journal of the Operational Research Society, vol. 57, no. 8, pp. 920-927, 2006.

[14] J. Yue, J. Austin, M.-C. Wang, and Z. Huang, "Coordination of cooperative advertising in a two-level supply chain when manufacturer offers discount," European Journal of Operational Research, vol. 168, no. 1, pp. 65-85, 2006.

[15] S. Karray and G. Zaccour, "Could co-op advertising be a manufacturer's counterstrategy to store brands?" Journal of Business Research, vol. 59, no. 9, pp. 1008-1015, 2006.

[16] J. Xie and S. Ai, "A note on 'Cooperative advertising, game theory and manufacturer-retailer supply chains"', Omega, vol. 34, no. 5, pp. 501-504, 2006.

[17] J. Xie and A. Neyret, "Co-op advertising and pricing models in manufacturer-retailer supply chains," Computers and Industrial Engineering, vol. 56, no. 4, pp. 1375-1385, 2009.

[18] J. Xie and J. C. Wei, "Coordinating advertising and pricing in a manufacturer-retailer channel," European Journal of Operational Research, vol. 197, no. 2, pp. 785-791, 2009.

[19] M. M. Seyedesfahani, M. Biazaran, and M. Gharakhani, “A game theoretic approach to coordinate pricing and vertical co-op advertising in manufacturer-retailer supply chains," European Journal of Operational Research, vol. 211, no. 2, pp. 263-273, 2011.

[20] A. Ahmadi-Javid and P. Hoseinpour, "On a cooperative advertising model for a supply chain with one manufacturer and one retailer," European Journal of Operational Research, vol. 219, no. 2, pp. 458-466, 2012.

[21] J. Yang, J. Xie, X. Deng, and H. Xiong, "Cooperative advertising in a distribution channel with fairness concerns," European Journal of Operational Research, vol. 227, no. 2, pp. 401-407, 2013.

[22] J. Zhang, J. Xie, and B. Chen, "Cooperative advertising with bilateral participation," Decision Sciences, vol. 44, no. 1, pp. $193-$ 203, 2013.

[23] P. K. Chintagunta and D. Jain, "A dynamic model of channel member strategies for marketing expenditures," Marketing Science, vol. 11, no. 2, pp. 168-188, 1992.

[24] S. Jørgensen, S. P. Sigué, and G. Zaccour, "Dynamic cooperative advertising in a channel," Journal of Retailing, vol. 76, no. 1, pp. 71-92, 2000.

[25] S. Jørgensen, S. Taboubi, and G. Zaccour, "Cooperative advertising in a marketing channel," Journal of Optimization Theory and Applications, vol. 110, no. 1, pp. 145-158, 2001.
[26] S. Jørgensen, S. Taboubi, and G. Zaccour, "Retail promotions with negative brand image effects: is cooperation possible?" European Journal of Operational Research, vol. 150, no. 2, pp. 395-405, 2003.

[27] S. Jorgensen and G. Zaccour, "Channel coordination over time: Incentive equilibria and credibility," Journal of Economic Dynamics and Control, vol. 27, no. 5, pp. 801-822, 2003.

[28] S. Karray and G. Zaccour, "A differential game of advertising for national and store brands," in Dynamic Games: Theory and Applications, vol. 10, chapter 11, pp. 213-229, Springer, New York, NY, USA, 2005.

[29] X. He, A. Prasad, and S. P. Sethi, "Cooperative advertising and pricing in a dynamic stochastic supply chain: feedback stackelberg strategies," Production and Operations Management, vol. 18, no. 1, pp. 78-94, 2009.

[30] J. Zhang, Q. Gou, L. Liang, and Z. Huang, "Supply chain coordination through cooperative advertising with reference price effect," Omega, vol. 41, no. 2, pp. 345-353, 2013.

[31] Y. He, Q. Gou, C. Wu, and X. Yue, "Cooperative advertising in a supply chain with horizontal competition," Mathematical Problems in Engineering, vol. 2013, Article ID 607184, 16 pages, 2013.

[32] K. Wang, Q. Gou, J. Sun, and X. Yue, "Coordination of a fashion and textile supply chain with demand variations," Journal of Systems Science and Systems Engineering, vol. 21, no. 4, pp. 461479, 2012.

[33] M. Bruce, L. Daly, and N. Towers, "Lean or agile: a solution for supply chain management in the textiles and clothing industry?" International Journal of Operations \& Production Management, vol. 24, no. 1-2, pp. 151-170, 2004.

[34] C.-H. Chiu, T.-M. Choi, H.-T. Yeung, and Y. Zhao, "Sales rebate contracts in fashion supply chains," Mathematical Problems in Engineering, vol. 2012, Article ID 908408, 19 pages, 2012.

[35] M. Huang, X. Wang, F.-Q. Lu, and H.-L. Bi, "A coordination of risk management for supply chains organized as virtual enterprises," Mathematical Problems in Engineering, vol. 2013, Article ID 931690, 11 pages, 2013.

[36] M. Xu, Q. Wang, and L. Ouyang, "Coordinating contracts for two-stage fashion supply chain with risk-averse retailer and price-dependent demand," Mathematical Problems in Engineering, vol. 2013, Article ID 259164, 12 pages, 2013.

[37] H. Peng and M. Zhou, "Quantity discount supply chain models with fashion products and uncertain yields," Mathematical Problems in Engineering, vol. 2013, Article ID 895784, 11 pages, 2013.

[38] Z. Cheng, J. Xiao, K. Xie, and X. Huang, "Optimal product quality of supply chain based on information traceability in fashion and textiles industry: an adverse logistics perspective," Mathematical Problems in Engineering, vol. 2013, Article ID 629363, 13 pages, 2013.

[39] M. Nerlove and K. J. Arrow, "Optimal advertising policy under dynamic conditions," Economica, vol. 29, no. 114, pp. 129-142, 1962.

[40] A. Gavious and O. Lowengart, "Price-quality relationship in the presence of asymmetric dynamic reference quality effects," Marketing Letters, vol. 23, no. 1, pp. 137-161, 2012.

[41] P. De Giovanni, "Quality improvement vs. advertising support: which strategy works better for a manufacturer?" European Journal of Operational Research, vol. 208, no. 2, pp. 119-130, 2011. 


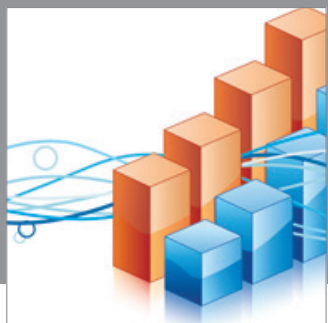

Advances in

Operations Research

mansans

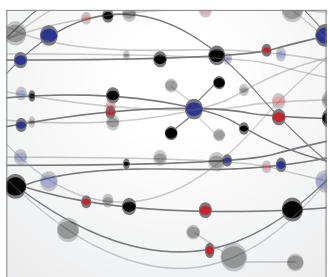

The Scientific World Journal
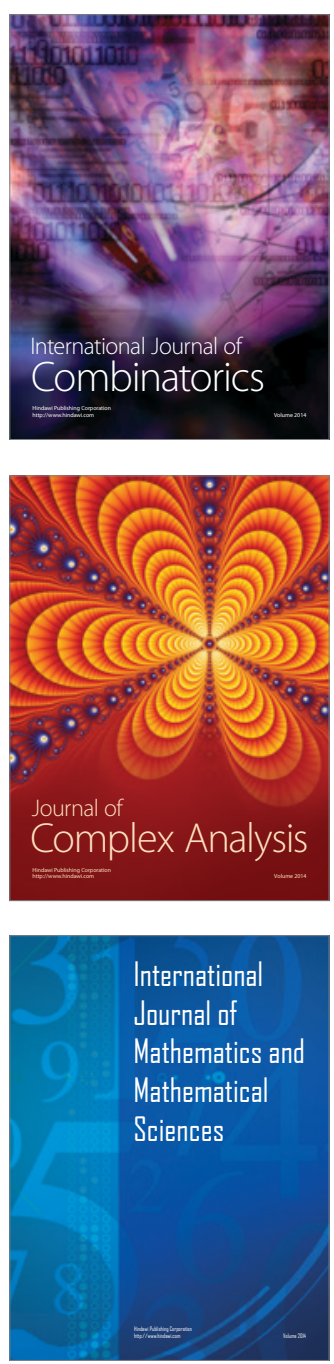
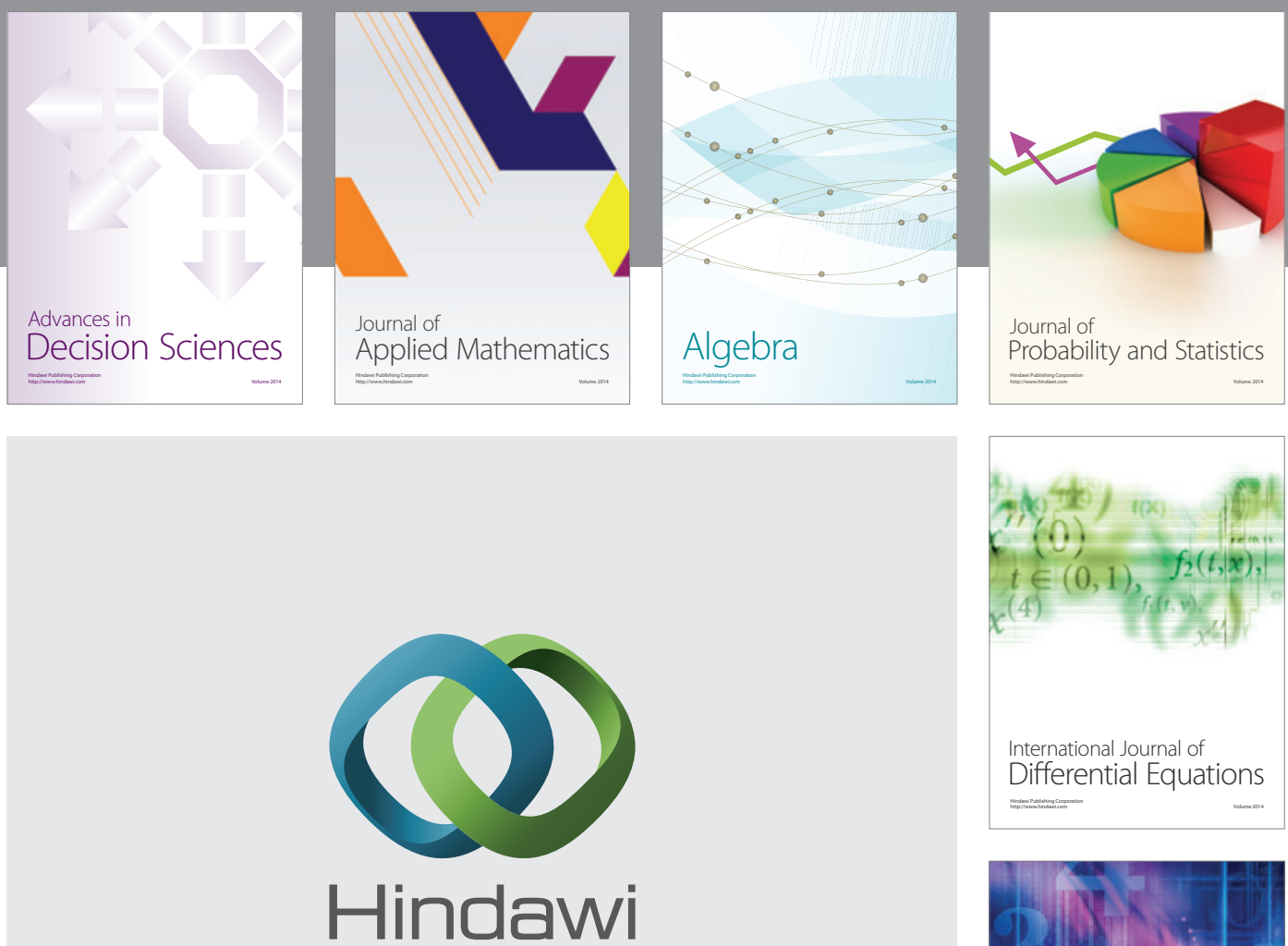

Submit your manuscripts at http://www.hindawi.com
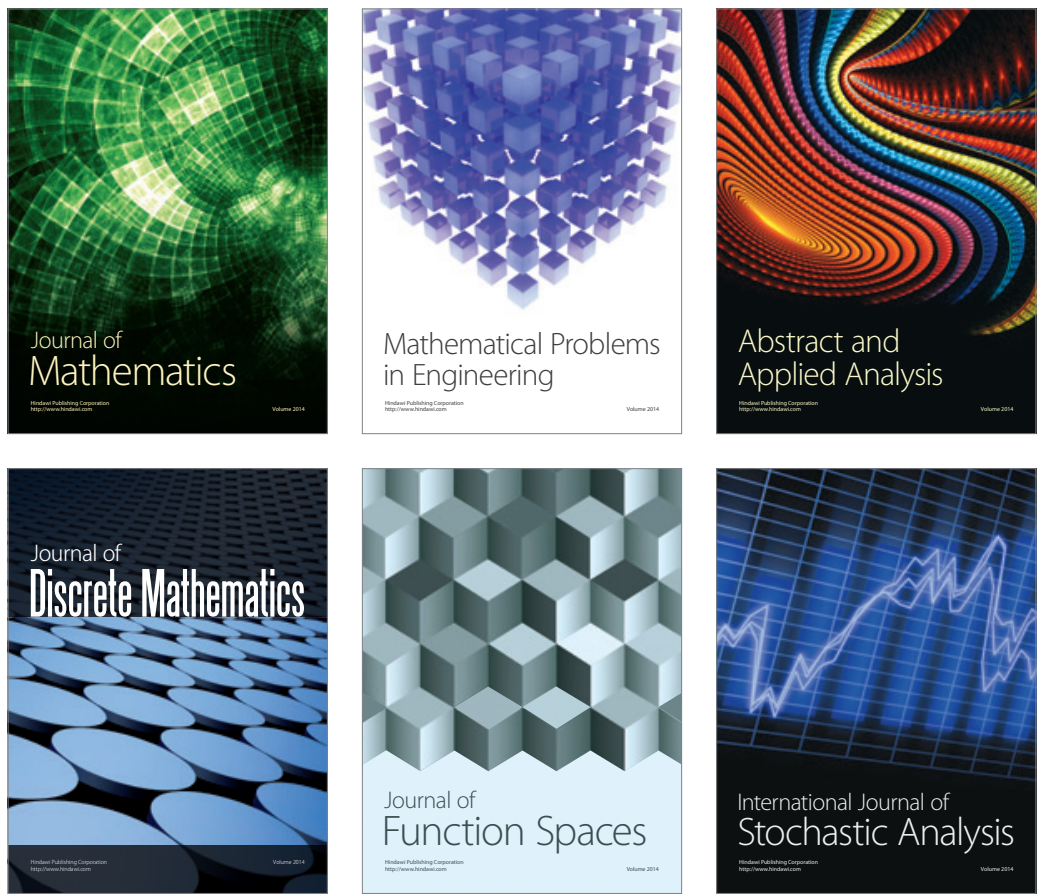

Journal of

Function Spaces

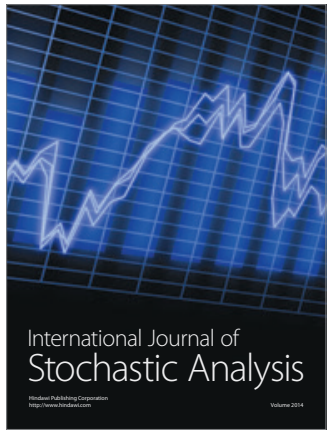

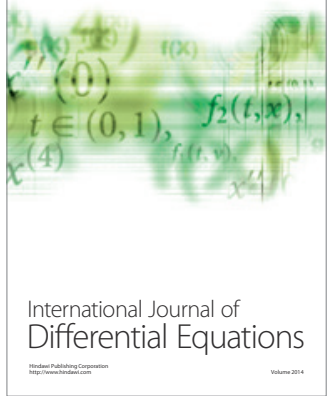
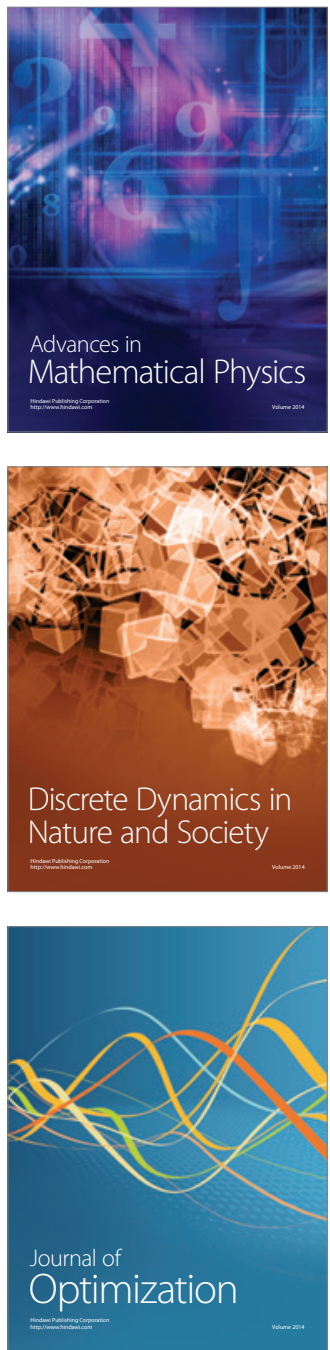